\title{
Effect of Fetal Adrenalectomy on Catecholamine Release and Physiologic Adaptation at Birth in Sheep
}

\author{
James Padbury, Youtaro Agata, John Ludlow, Machiko Ikegami, Barry Baylen, and James Humme \\ Perinatal Research Laboratories, Department of Pediatrics, University of California \\ at Los Angeles Harbor Medical Center, Torrance, California 90509
}

\begin{abstract}
Plasma catecholamine levels increase dramatically at birth. To determine the contribution of adrenal catecholamine secretion to the surge in catecholamines at birth and the role in newborn adaptation, we performed surgical adrenalectomy or sham operation on near-term ovine fetuses. After recovery in utero, the animals were delivered and supported by mechanical ventilation. Plasma catecholamine levels, heart rate, blood pressure, cardiac output, pulmonary function, surfactant secretion, and release of free fatty acids (FFA) and glucose were compared in control and adrenalectomized animals. Plasma epinephrine increased rapidly at birth in controls but was undetectable in adrenalectomized animals. Norepinephrine levels were not statistically different. Heart rate, blood pressure, cardiac output and contractility increased abruptly after cord cutting in controls but did not increase in adrenalectomized animals. Lung compliance, pulmonary function, surfactant pool size, glucose and FFA levels were significantly decreased in adrenalectomized animals. These results suggest that adrenal epinephrine secretion is vital to many of the adaptive events at birth.
\end{abstract}

\section{Introduction}

With birth and umbilical cord cutting there is a sudden increase in systemic blood pressure, closure of fetal shunts, and an increase in cardiac output and cardiac performance (1). Additional adaptive events occur including surfactant secretion and clearance of lung water, increased hepatic glucose output, onset of nonshivering (chemical) thermogenesis and free fatty acid mobilization. Available evidence suggests that these adaptive events are, at least in part, conditioned upon adrenergic receptor stimulation.

Previous studies have shown striking elevations of plasma catecholamine levels (CA) ${ }^{1}$ at birth in both animals and humans (2-4). A marked umbilical artery to umbilical vein concentration gradient suggests a fetal origin for the cord plasma catecholamines. This is supported by previous studies

Address reprint requests to Dr. Padbury, Harbor-UCLA Medical Center, 1000 West Carson Street, Torrance, CA 90509.

Received for publication 14 January 1987 and in revised form 23 April 1987.

1. Abbreviations used in this paper: ANOVA, analysis of variance; CA, catecholamine; E, epinephrine; NE, norepinephrine; SPC, saturated phosphatidylcholine; VEI, ventilation efficiency index.

J. Clin. Invest.

(c) The American Society for Clinical Investigation, Inc.

0021-9738/87/10/1096/08 \$2.00

Volume 80, October 1987, 1096-1103 suggesting little if any transplacental passage of catecholamines (5). In the chronically catheterized ovine fetus, elevations in plasma norepinephrine (NE) and epinephrine (E) concentrations have been demonstrated during the last 2-3 h of spontaneous labor preceding delivery (6). There is then a 4-10-fold augmentation of plasma levels of both NE and E after delivery and cord cutting (7).

To more precisely define the contribution of adrenal catecholamine secretion to this catecholamine surge at birth and the role in newborn adaptation, we performed surgical adrenalectomy on near-term ovine fetuses. After operative recovery the animals were delivered and the changes in plasma catecholamine levels, heart rate, blood pressure, cardiac output, pulmonary function, pulmonary surfactant secretion and release of free fatty acids (FFA) and glucose were compared in adrenalectomized and sham-operated newborns.

\section{Methods}

Animal preparation and adrenalectomy. 17 Western, mixed-breed ewes with date-bred singleton pregnancies were obtained from a local supplier (Nebeker Farms, Lancaster, CA). The animals were housed indoors and acclimated to the laboratory environment prior to surgery. On the day before surgery, food (alfalfa pellets) was withheld but the ewe was allowed access to water. At $138 \pm 1$ d gestation, the ewes were sedated with ketamine (750 $\mathrm{mg}$ i.m.) and atropine (1.2 $\mathrm{mg}$ i.m.) and then anesthetized with a continuous infusion of intravenous ketamine at $8-10 \mathrm{mg} / \mathrm{min}$. The abdomen was shaved and prepped and the uterus exposed through a midline longitudinal incision. Adrenalectomy was carried out with modifications of the technique described by Liggins et al. (8). The uterine horn containing the fetus was delivered onto the maternal abdomen with care to avoid traction or torsion of the lower uterine segment. Fetal parts were identified by palpation and the exposed uterus was covered with warm saline-soaked gauze.

A single hysterotomy incision was made over the fetal spine and the fetal skin overlying the costovertebral region was marsupialized to the uterine incision with atraumatic clamps. After infiltration of fetal skin with $1 \%$ lidocaine, an incision was made over the fetal costovertebral region. The subcutaneous tissue was separated by blunt dissection anterior to the paraspinous muscle groups and the lateral abdominal wall musculature and peritoneum were opened. Warm saline-soaked gauze packing and retractors were used to expose the adrenal in the retroperitoneal space superior to the kidney. The adrenal was gradually mobilized by blunt dissection while its vascular supply was crossclamped with microvascular clips (Ethicon Inc., Raritan, NJ). The entire adrenal was removed and wound closure was carried out in layered fashion. The fetus was gently rotated within the uterus and the opposite adrenal was removed similarly through a second costovertebral incision.

Fetuses were randomly assigned to undergo either bilateral adrenalectomy or a sham operative procedure during which each adrenal gland was fully exposed in a similar fashion. After completion of the second adrenalectomy, an osmotic mini-infusion pump (Alza Corp., Palo Alto, CA), programmed to deliver hydrocortisone hemisuccinate base at $0.9 \mathrm{mg}$ per $24 \mathrm{~h}$ for $1 \mathrm{wk}$, was inserted subcutaneously in each 
adrenalectomized fetus and the final skin layer was repaired. Shamoperated animals did not receive a pump. The uterine incision was closed and the uterus returned into the abdominal cavity. The maternal incision was closed in layers and the ewe and fetus allowed to recover. Methicillin ( $1 \mathrm{~g}$ i.m.) and gentamycin $(80 \mathrm{mg}$ i.m.) were given twice daily to the ewe.

Delivery studies. After 3-4 d of postoperative recovery, the ewe was sedated with ketamine $(700 \mathrm{mg})$ and atropine $(1.2 \mathrm{mg})$ and, following local skin infiltration ( $1 \%$ lidocaine), a maternal femoral arterial cutdown and tracheostomy were performed. The ewe was given additional intravenous ketamine $(300 \mathrm{mg}), 1 \mathrm{mg}$ of pancuronium bromide (Pavulon, Organon Teknika Corp., Aurora, CA) and placed on an animal respirator (Harvard Apparatus Corp., Natick, MA) on $40 \%$ oxygen. The tidal volume and rate were adjusted to maintain $\mathrm{pH}$ and $\mathrm{PCO}_{2}$ in the normal range. The uterus was exposed through the original abdominal incision and the fetal head identified by palpation. A small uterine incision was made and the fetal head was delivered and covered with a rubber glove. After local infiltration of the fetal neck (1\% lidocaine), a midline incision was made and a tracheostomy was performed with secure placement of a clamped, uncuffed $5.0 \mathrm{~mm}$ Portex endotracheal tube. The right carotid artery was catheterized with a rigid, 5 French polyethylene catheter that was connected to a pressure transducer and advanced under oscilloscopic monitoring into the left ventricle. The catheter was secured in place and the fetus was delivered onto the maternal abdomen with care to avoid traction or trauma to the umbilical cord and allowed to stabilize as described previously (7). $7-10 \mathrm{ml}$ of clear tracheal fluid were removed and mixed with $2 \mu \mathrm{Ci}$ $\left[{ }^{3} \mathrm{H}\right]$ choline labeled sheep natural surfactant. The $\left[{ }^{3} \mathrm{H}\right]$ choline labeled surfactant was isolated by density gradient centrifugation from alveolar washes from lungs of a 3-d-old lamb $36 \mathrm{~h}$ after injection with $15 \mathrm{mCi}$ $\left[{ }^{3} \mathrm{H}\right]$ choline (New England Nuclear, Boston, MA) intravenously (9). Heart rate and blood pressure were determined continuously with a pressure transducer connected to the arterial catheter and temperature was maintained with a heating pad and lamps.

Arterial blood samples for catecholamines, blood gases, FFA, and glucose were drawn immediately after catheterization, serially after delivery until the time of cord cutting and sequentially thereafter as previously described (7). Just prior to umbilical cord cutting and prior to the first breath, $\left[{ }^{3} \mathrm{H}\right]$ choline labeled surfactant mixed with tracheal fluid was instilled directly into the endotracheal tube followed by $5 \mathrm{~cm}^{3}$ of air, with care to avoid any loss of the radiolabeled surfactant. Immediately following umbilical cord cutting the animals were placed on time-cycled, pressure limited Sechrist infant ventilators (Sechrist Industries, Inc., Anaheim, CA). To prevent movement, the animals were paralyzed with pancuronium bromide. The lambs were dried and cared for under an infant radiant warmer with supplemental heat lamps as necessary to maintain rectal temperature at $39 \pm 1{ }^{\circ} \mathrm{C}$. An umbilical arterial catheter was inserted to the level of the midabdominal aorta for monitoring and blood sampling. Heart rate and blood pressure were measured continuously via the umbilical artery catheter and recorded on a multichannel Sensormedic R611 rectilinear polygraph (Sensormedics Corp., Anaheim, CA). Peak left ventricular (LV) derivative of pressure with respect to time $d P / d t$ was measured with a calibrated $9879 d P / d t$ coupler and recorded continuously on a separate channel. Blood samples for measurement of plasma catecholamine levels, arterial blood gases, FFA, and glucose were obtained from the umbilical artery catheter at 5, 15, 30,60,120,180, and 240 min after cord cutting. Heart rate, blood pressure, peak $L V d P / d t$ and temperature were recorded with each sample. Initial ventilator settings (peak inspiratory pressure $28 \mathrm{~cm} \mathrm{H}_{2} \mathrm{O}$, positive end expiratory pressure $2 \mathrm{~cm}$ $\mathrm{H}_{2} \mathrm{O}$ and a rate of $30 / \mathrm{min}$ ) were adjusted to maintain $\mathrm{PO}_{2}$ between 100 and 150 torr and $\mathrm{pH}$ and $\mathrm{PCO}_{2}$ within normal values. A continuous infusion of normal saline at $4 \mathrm{ml} / \mathrm{kg}$ per h was administered. Transfusions for blood replacement were given after each blood sample with heparinized, residual placental blood drawn following delivery.

At $30 \mathrm{~min}, 1 \mathrm{~h}$ and hourly thereafter, expiratory tidal volume was measured with a 2/0 Fleisch pneumotachygraph using a Validyne pressure transducer and electronic integration (Validyne Engineering
Corp., Northridge, CA). After tidal volume measurements, an airway suction sample was obtained by instillation of $0.5-1.0 \mathrm{ml}$ of $0.9 \%$ sodium chloride into the endotracheal tube followed three breaths later by endotracheal suctioning with a catheter attached to a vacuum trap. The aspirated material was diluted to $2 \mathrm{ml}$ with saline, extracted with 2 $\mathrm{ml}$ methanol plus $4 \mathrm{ml}$ chloroform and kept at $-20^{\circ} \mathrm{C}$ for later surfactant phospholipid and radioactivity analysis (10).

At 30,90 , and 240 min after umbilical cord cutting, left ventricular output was determined by injection of ${ }^{125} \mathrm{I},{ }^{85} \mathrm{Sr}$, or ${ }^{46} \mathrm{Sc}$ labeled $15-\mu \mathrm{m}$ microspheres (New England Nuclear, Boston, MA). The microspheres were suspended in $6 \mathrm{ml}$ heparinized blood that was infused into the left ventricle over $60 \mathrm{~s}$. Concurrent with each injection of microspheres, a reference sample was withdrawn into a preweighed, heparinized glass syringe at a rate of $6 \mathrm{ml} / \mathrm{min}$ for $2 \mathrm{~min}$ from the descending aorta. The volume withdrawn was replaced simultaneously with heparinized blood.

Postmortem analyses. At $4 \mathrm{~h}$ of age, the animals were killed by intravenous overdose of sodium pentobarbital $(100 \mathrm{mg} / \mathrm{kg})$ and exsanguinated by cutting the abdominal aorta. The endotracheal tube was clamped and the lambs were weighed. The lung was removed en bloc and weighed. Alveolar wash was recovered after three repeated distentions and withdrawals from the lungs of a single volume of $0.9 \%$ sodium chloride. This alveolar wash was pooled with four more repeated procedures with fresh $0.9 \%$ sodium chloride (9). The total volume was recorded and an aliquot saved.

After removal of the lungs, the heart, liver, kidneys, and gastrointestinal tract were removed, weighed, and frozen separately.

Analytical techniques. Plasma catecholamine concentrations were determined by radioenzymatic assay sensitive to $10-20 \mathrm{pg} / \mathrm{ml}$ of norepinephrine and epinephrine (11). Blood gases were measured on a blood gas instrument (BMS3 MKII, Radiometer Copenhagen, Copenhagen, Denmark) calibrated at $39^{\circ} \mathrm{C}$. Free fatty acids were measured using a microcolorimetric assay (12). Glucose was measured with a 23A-YSI glucose analyzer (Yellow Springs Instruments Co., Yellow Springs, $\mathrm{OH}$ ).

After chloroform/methanol extraction, the lipids in the airway suction samples, alveolar wash, and lung homogenate were concentrated by evaporation under nitrogen and saturated phosphatidylcholine (SPC) was recovered from the lipid extracts following exposure to osmium tetroxide by alumina column chromatography. The recovered SPC was divided for measurements of radioactivity and phosphate content (10). Specific activity, measured on aliquots of the ${ }^{3} \mathrm{H}$-surfactant tracer given to each lamb, was used to calculate total recovery of radioactivity and surfactant pool size from airway suction samples, alveolar wash, and lung homogenate as described previously (9).

For microsphere determinations, the carcass and each organ were ashed separately and the radioactivity measured in a multichannel gamma spectrometer (Compu Gamma, LKB Instruments, Inc., Gaithersburg, MD). The left ventricular output (milliliters per minute per kilogram body weight) and organ blood flow (milliliters per minute per $100 \mathrm{~g}$ tissue) were calculated from the amount of microspheres in the reference blood samples and the total amounts of microspheres injected. Total systemic resistance was calculated from the cardiac output and the mean arterial pressure at the time of injection.

Total lung compliance per kilogram was calculated by dividing the measured tidal volume by the pressure change of the ventilator and the weight of the lamb. Ventilation efficiency index $(V E I)$ was calculated according to Notter et al. (13). This index relates alveolar ventilation to required respirator input by including the ventilator rate $(f)$, pressure $(\Delta P$, peak minus end expiratory pressure), diffusion constant $(3,800)$ and arterial $\mathrm{PCO}_{2}$ and is calculated by the following formula: $V E I$ $=3,800 / \Delta P \cdot f \cdot \mathrm{PCO}_{2}$. Higher VEI values indicate better pulmonary function.

Data analysis. Serial plasma catecholamine values, cardiovascular parameters, pulmonary function tests, FFA values, and plasma glucose levels were compared by two-way analysis of variance (ANOVA), factor A (treatment) and factor B (time after cord cutting) (14). Peak values of each parameter and/or individual comparisons were com- 
pared by unpaired Student $t$ test as indicated (14). All results are shown as mean \pm SEM.

\section{Results}

A total of 17 animals underwent adrenalectomy or sham operation. One animal was discovered to have only partial adrenalectomy and was deleted from the study. One control died shortly after delivery from accidental airway occlusion; two adrenalectomized animals died, one postoperatively in utero and one during surgery. The remaining seven control and six adrenalectomized animals were delivered at $141 \pm 0.5 \mathrm{~d}$ gestation and results from these animals are shown.

Serial plasma CA values from control and adrenalectomized animals are shown in Fig. 1. Plasma epinephrine levels are shown in the upper panel. In control animals, plasma epinephrine rose abruptly from $70 \mathrm{pg} / \mathrm{ml}$ before cord cutting to $>1,000 \mathrm{pg} / \mathrm{ml}$ by $15 \mathrm{~min}$ and remained elevated for the remainder of the study period. Plasma epinephrine was undetectable in the adrenalectomized animals. These differences between mean plasma epinephrine concentrations in control and adrenalectomized animals were highly significant $(P$ $<0.001$, ANOVA). The epinephrine values in control animals are comparable to values noted previously in intact animals of this gestational age (7). Plasma norepinephrine values are shown in the lower panel of Fig. 1. Norepinephrine increased rapidly in plasma of control animals, from 350 to $400 \mathrm{pg} / \mathrm{ml}$ to nearly $1,000 \mathrm{pg} / \mathrm{ml}$ by $30 \mathrm{~min}$. Plasma norepinephrine in adrenalectomized animals rose from comparable baseline values to $>500 \mathrm{pg} / \mathrm{ml}$ by $60 \mathrm{~min}$ of age. There was a further gradual increase over the next 120 min to a maximum of
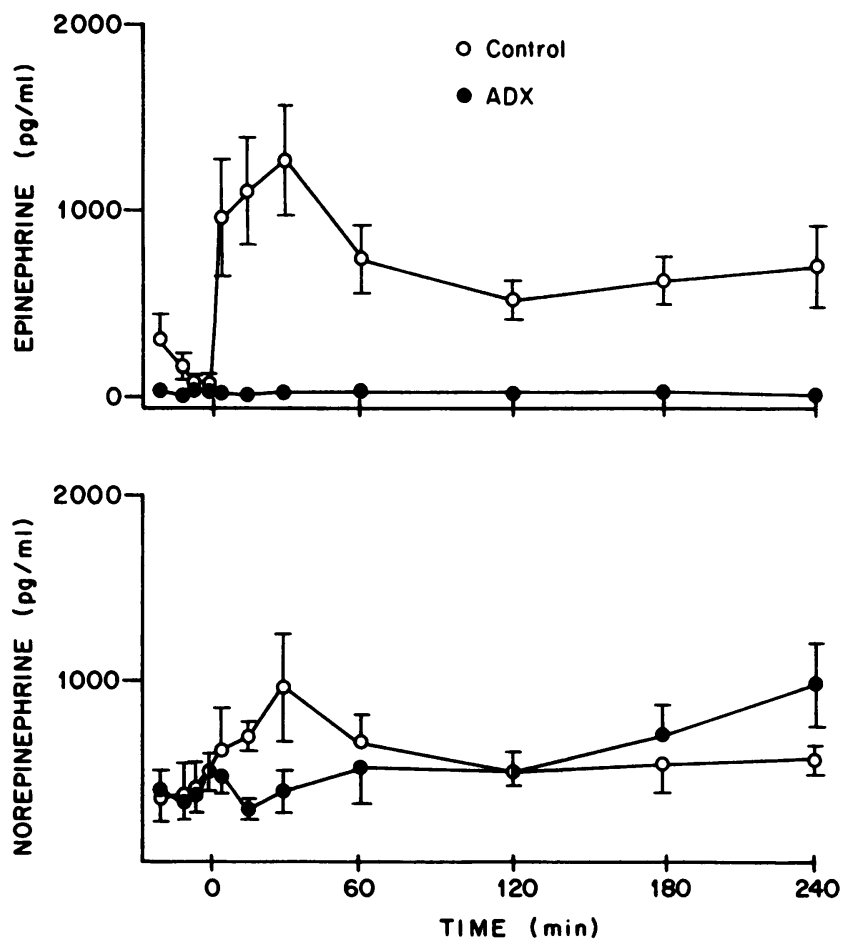

Figure 1. Plasma epinephrine and norepinephrine in control (0) and adrenalectomized $(\bullet)$ animals. Zero time refers to umbilical cord cutting. Animal preparation and assays as described in Methods.
$975 \pm 226 \mathrm{pg} / \mathrm{ml}$ at $240 \mathrm{~min}$ of age. These differences were not significant by two-way ANOVA.

Serial blood pressure, peak LV $d P / d t$ and heart rate are shown in Fig. 2. Peak systolic blood pressure rose rapidly in control animals from a baseline of $63 \pm 3$ (prior to cord cutting) to $89 \pm 6 \mathrm{mmHg}$ maximum. Baseline blood pressure in adrenalectomized animals $(55 \pm 3 \mathrm{mmHg}$ ) was significantly lower than in controls and did not rise appreciably following umbilical cord cutting. Comparison by two-way ANOVA was highly significant $(P<0.001)$. Peak LV $d P / d t$ showed similar alterations. Peak LV $d P / d t$ in control animals rose rapidly following cord cutting to a maximum of $4,000 \pm 340 \mathrm{mmHg} / \mathrm{s}$, whereas peak $L V \mathrm{dP} / \mathrm{dt}$ in adrenalectomized animals showed little or no change throughout the period of the study from the initial value of $1,200 \pm 200 \mathrm{mmHg} / \mathrm{s}(P<0.01$, ANOVA). In control animals a brief period of tachycardia during exteriorization to $188 \pm 19$ beats/min was followed by stabilization at $151 \pm 22$ beats/min. Following cord cutting heart rate rose in control animals to $193 \pm 11$ beats $/ \mathrm{min}$. Adrenalectomized animals, by contrast, showed little heart rate response to exteriorization or cord cutting. Heart rate in the adrenalectomized animals gradually increased over the course of the experiment to values comparable to the control animals by 3 and $4 \mathrm{~h}$, however, the overall heart rate values were greater in control animals $(P<0.05$, ANOVA). Left ventricular end diastolic pressure was similar in the two groups, $6.1 \pm 0.7 \mathrm{mmHg}$ in controls versus $5.1 \pm 0.4 \mathrm{mmHg}$ in adrenalectomized animals, and did not change appreciably during the study.

Left ventricular output (LVO) ( $\mathrm{ml} / \mathrm{min}$ per $\mathrm{kg})$, stroke volume $(\mathrm{ml} / \mathrm{kg})$, systemic vascular resistance $(\mathrm{mmHg} / \mathrm{ml} \mathrm{per} \min$ per $\mathrm{kg}$ ) and regional blood flow distribution $(\mathrm{ml} / \mathrm{min}$ per 100 g) are shown in Table I LVO in control animals at $\mathbf{3 0 ~ m i n ~ o f ~}$ age, $277 \pm 16 \mathrm{ml} / \mathrm{min}$ per $\mathrm{kg}$, was well above reported fetal values and comparable to values reported for intact animals at

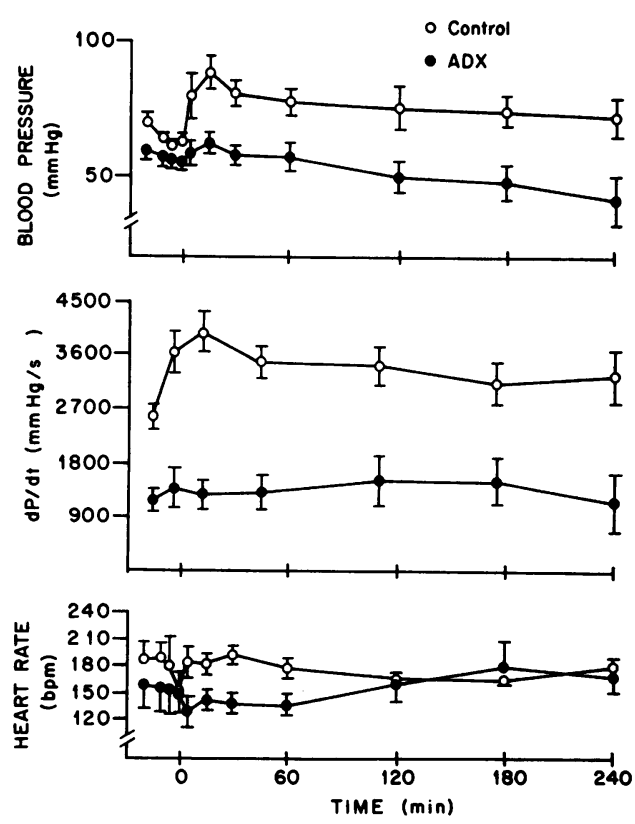

Figure 2. Systolic blood pressure $(\mathrm{mmHg})$, peak left ventricular $d P / d t(\mathrm{mmHg} / \mathrm{s})$ and heart rate (beats per min) in control (o) and adrenalectomized (๑) animals. Zero time refers to umbilical cord cutting. Animal preparation and monitoring as described in Methods. 
Table I. Left Ventricular Output ( $\mathrm{ml} / \mathrm{min} / \mathrm{kg})$, Stroke Volume $(\mathrm{ml} / \mathrm{kg})$, Systemic Vascular Resistance $(\mathrm{mmHg} / \mathrm{ml} / \mathrm{min} / \mathrm{kg})$, and Organ Blood Flow ( $\mathrm{ml} / \mathrm{min} / 100 \mathrm{~g}$ tissue) at 30, 90, and $240 \mathrm{~min}$ after Umbilical Cord Cutting

\begin{tabular}{|c|c|c|c|c|c|c|c|c|c|}
\hline \multirow[b]{2}{*}{ Minutes } & \multicolumn{3}{|c|}{ Left ventricular output } & \multicolumn{3}{|l|}{ Stroke volume } & \multicolumn{3}{|c|}{ Systemic vascular resistance } \\
\hline & 30 & 90 & 240 & 30 & 90 & 240 & 30 & 90 & 240 \\
\hline Control $(n=7)$ & $277 \pm 16$ & $195 \pm 15$ & $176 \pm 13$ & $1.37 \pm 0.14$ & $1.22 \pm 1.20$ & $1.00 \pm 0.05$ & $0.24 \pm 0.02$ & $0.33 \pm 0.04$ & $0.32 \pm 0.03$ \\
\hline \multirow[t]{2}{*}{ Adrenalectomized $(n=6)$} & $169 \pm 22^{*}$ & $136 \pm 13^{\ddagger}$ & $120 \pm 25^{\ddagger}$ & $1.24 \pm 0.15$ & $0.96 \pm 0.12$ & $0.77 \pm 0.19$ & $0.30 \pm 0.06$ & $0.33 \pm 0.07$ & $0.30 \pm 0.07$ \\
\hline & \multicolumn{3}{|c|}{ Myocardial blood flow } & \multicolumn{3}{|c|}{ Gastrointestinal blood flow } & \multicolumn{3}{|c|}{ Renal blood flow } \\
\hline Control & $247 \pm 54$ & $194 \pm 30$ & $130 \pm 14$ & $56 \pm 6$ & $38 \pm 4$ & $48 \pm 6$ & $188 \pm 19$ & $117 \pm 19$ & $73 \pm 21$ \\
\hline \multirow[t]{2}{*}{ Adrenalectomized } & $158 \pm 32$ & $125 \pm 24^{*}$ & $89 \pm 17^{*}$ & $22 \pm 5^{\ddagger}$ & $18 \pm 5^{*}$ & $20 \pm 2 *$ & $37 \pm 4^{\ddagger}$ & $35 \pm 5^{\ddagger}$ & $47 \pm 21^{*}$ \\
\hline & \multicolumn{3}{|c|}{ Hepatic blood flow } & & & & & & \\
\hline Control & $23 \pm 6$ & $55 \pm 7$ & $33 \pm 13$ & & & & & & \\
\hline Adrenalectomized & $24 \pm 10$ & $52 \pm 14$ & $22 \pm 5$ & & & & & & \\
\hline
\end{tabular}

Blood flow and cardiac output were determined by injection of radionuclide-labeled microspheres as described in Methods. Values represent mean \pm SEM. ${ }^{*} P<0.05$ adrenalectomized vs. control animals. ${ }^{\ddagger} P<0.01$ adrenalectomized vs. control animals.

birth at this gestational age $(15,16)$. LVO at $30 \mathrm{~min}$ in adrenalectomized animals, $169 \pm 22 \mathrm{ml} / \mathrm{min}$ per $\mathrm{kg}$, was $39 \%$ less than control animals and remained significantly below control animals at each determination $(P<0.005$, ANOVA). Stroke volume in milliliters per kilogram was greater in control than adrenalectomized animals at each determination, however, these differences did not achieve statistical significance, $(0.05$ $<P<0.1)$. Systemic vascular resistance $(\mathrm{mmHg} / \mathrm{ml}$ per $\mathrm{min}$ per $\mathrm{kg}$ ) was similar in the two groups.

Regional blood flows to heart, kidney, liver, and gastrointestinal tract at 30, 90, and 240 min are also shown in Table I. Blood flow to the heart, kidneys, and gastrointestinal tract was significantly reduced in adrenalectomized animals. These reductions averaged $50 \%$ for renal blood flow and $50 \%$ for gastrointestinal blood flow. Myocardial blood flow was $30 \%$ less in adrenalectomized animals; this difference was significant at 90 and $240 \mathrm{~min}$. Hepatic blood flow was similar in the two groups.
The serial arterial blood gas values, lung compliance and VEI are shown in Fig. 3. Initial arterial blood gas and pH values were similar in control and adrenalectomized animals (pH 7.35 vs. $7.37, \mathrm{PO}_{2} 30 \pm 2$ vs. $30 \pm 3$ and $\mathrm{PCO}_{2} 42 \pm 3$ vs. $42 \pm 1$ torr, respectively). After delivery, despite attempts to maintain comparable degrees of oxygenation and acid-base status, there was a gradual development of metabolic acidosis in the adrenalectomized animals with a mean $\mathrm{pH}$ of $7.30 \pm 0.05$ by 240 min of age. This occurred despite attempts at ventilatory correction, with higher peak inspiratory pressures and more rapid rates being used in the adrenalectomized animals. Arterial blood gas values in control animals remained within the normal range throughout the study period. Total lung compliance was greater in control animals throughout the period of study $(P<0.05)$. VEI was also greater in control than in adrenalectomized animals by $60 \mathrm{~min}(0.24 \pm 0.03$ vs. $0.16 \pm 0.02, P$ $<0.05$ ) and remained greater thereafter.

Serial measurements of $\left[{ }^{3} \mathrm{H}\right]$ choline labeled surfactant spe-

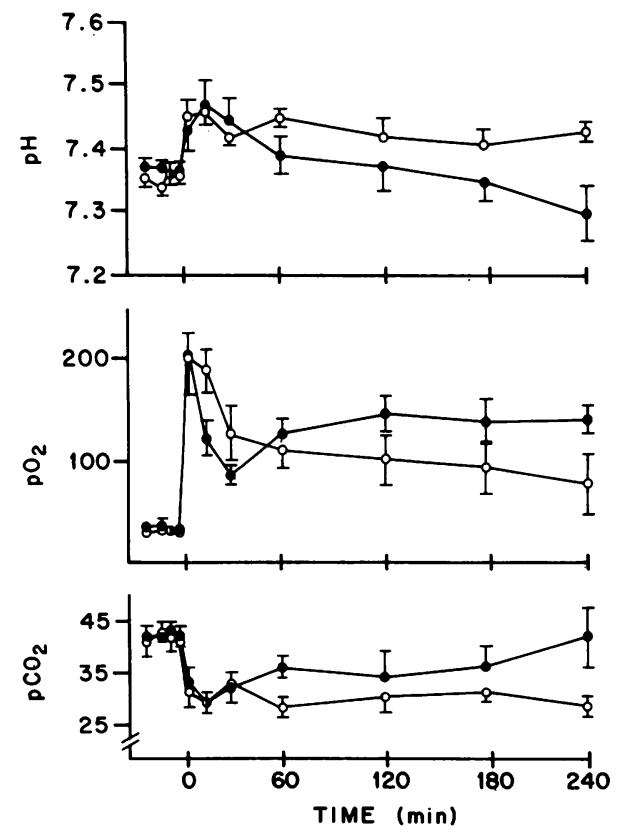

Figure 3. Arterial $\mathrm{pH}, \mathrm{PO}_{2}$ and $\mathrm{PCO}_{2}$, compliance $(\mathrm{ml} / \mathrm{kg}$ per $\mathrm{cmH}_{2} \mathrm{O}$ ) and VEI ( $\mathrm{ml} /$ torr per $\mathrm{kg}$ ) in control (O) and adrenalectomized $(\bullet)$ animals. VEI is an index which relates degree of alveolar ventilation to respirator input (reference 13). Ventilation was begun after cord cutting at zero time as described in Methods. 
Table II. Surfactant Pool Size ( $\mu \mathrm{mol}$ SPC/kg, Mean \pm SE) in Control and Adrenalectomized Animals from Airway Suction Samples, Alveolar Wash, and Lung Homogenate

\begin{tabular}{|c|c|c|c|c|c|}
\hline Minutes & 30 & 60 & 120 & 180 & 240 \\
\hline Control & $3.6 \pm 0.5$ & $7.7 \pm 1.5$ & $12.5 \pm 2.5$ & $15.5 \pm 2.9$ & $19.5 \pm 3.4$ \\
\hline \multirow[t]{2}{*}{ Adrenalectomized } & $3.4 \pm 0.8$ & $6.6 \pm 2.0$ & $9.8 \pm 1.7$ & $13.2 \pm 3.0$ & $15.6 \pm 2.8$ \\
\hline & \multicolumn{2}{|c|}{$\begin{array}{l}\text { Alveolar wash SPC } \\
\mu \mathrm{mol} / \mathrm{kg}\end{array}$} & \multicolumn{2}{|l|}{ Lung tissue } & $\begin{array}{l}\text { Total lung } \\
\text { (alveolar wash + lung) }\end{array}$ \\
\hline Control & \multicolumn{2}{|c|}{$30.2 \pm 2.9$} & \multicolumn{2}{|l|}{$135.6 \pm 9.0$} & $165.8 \pm 10.0$ \\
\hline Adrenalectomized & \multicolumn{2}{|c|}{$15.6 \pm 2.8^{*}$} & \multicolumn{2}{|l|}{$130.0 \pm 18.2$} & $145.6 \pm 19.7$ \\
\hline
\end{tabular}

Calculated surfactant pool size in airway from airway suction samples $\mathrm{SPC} / \mathrm{kg}(\mu \mathrm{mol} \mathrm{SPC} / \mathrm{kg}) * P<0.005$ adrenalectomized vs. control.

cific activity were used to calculate alveolar pool size from each airway suction sample. These results are shown in Table II. Surfactant pool size in micromoles SPC per kilogram increased in control and adrenalectomized animals from $3.6 \pm 0.5$ vs. $3.4 \pm 0.8 \mu \mathrm{mol} / \mathrm{kg}$ at $30 \mathrm{~min}$ to $19.5 \pm 3.0 \mathrm{vs}$. $15.9 \pm 2.2 \mu \mathrm{mol} / \mathrm{kg}$ at $240 \mathrm{~min}$, respectively. These values are based on isotope dilution techniques with the assumptions of no loss of tracer from the alveolar space and rapid homogenous mixing with the endogenous pool (10). These assumptions are difficult to validate or correct for, therefore alveolar lavage was performed at the end of each experiment for direct measurements of alveolar SPC. When actual surfactant pool sizes were determined directly from the postmortem alveolar wash, the differences were more striking. Surfactant pool size was nearly twofold greater in control than adrenalectomized animals, $30.2 \pm 2.9$ vs. $15.6 \pm 2.8 \mu \mathrm{mol} \mathrm{SPC} / \mathrm{kg}(P<0.01)$. Total lung surfactant values, measured from lung homogenates after alveolar wash, also were compared in control and adrenalectomized animals (Table II). Total SPC in lung homogenate after alveolar wash in control animals (135.6 $\pm 9.0 \mu \mathrm{mol} \mathrm{SPC/}$
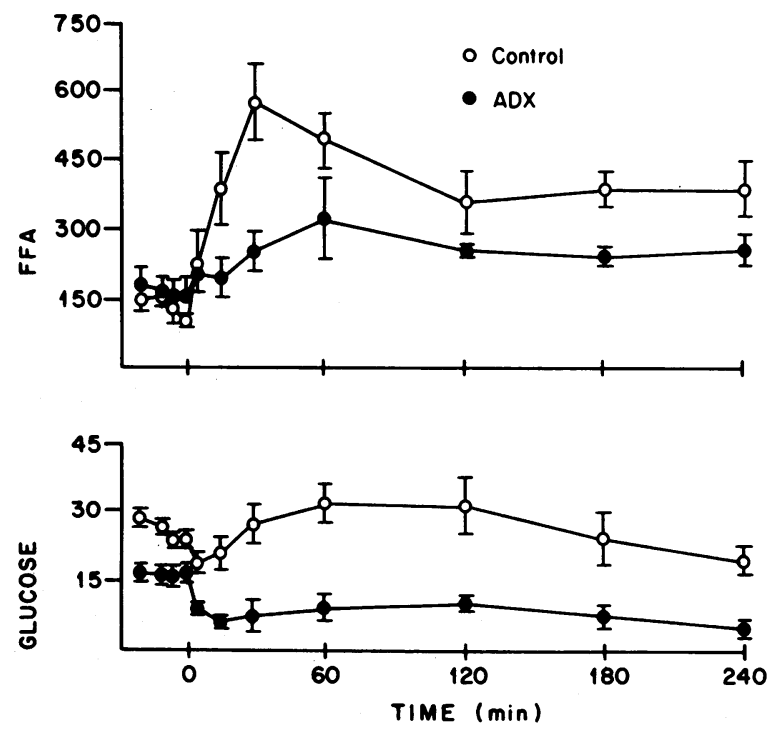

Figure 4. Plasma FFA ( $\mu \mathrm{eq} /$ liter) and glucose (mg/dl) after exteriorization (baseline) and umbilical cord cutting (zero time). Assays as described in Methods. Significant differences were noted in peak FFA concentration $(P<0.005)$, overall FFA response $(P<0.001)$, peak glucose concentration $(P<0.05)$ and overall glucose response $(P<0.005)$. $\mathrm{kg})$ was similar to adrenalectomized animals (130.0 \pm 18.2 $\mu \mathrm{mol} \mathrm{SPC} / \mathrm{kg}$ ), as was the sum of alveolar and lung tissue surfactant (165.6 \pm 10.0 vs. $145.6 \pm 19.7 \mu \mathrm{mol} \mathrm{SPC} / \mathrm{kg})$.

Comparisons of serial FFA and plasma glucose are shown in Fig. 4. Baseline FFA in control and adrenalectomized animals were comparable, $101 \pm 17$ vs. $156 \pm 36 \mu \mathrm{eq} /$ liter, respectively. After cord cutting, FFA rose abruptly in control animals to a peak of $577 \pm 84 \mu \mathrm{eq} / \mathrm{liter}$ at $30 \mathrm{~min}$. The FFA response in adrenalectomized animals was relatively blunted, rising gradually to a maximum of $323 \pm 87 \mu \mathrm{eq} / \mathrm{liter}$ at $60 \mathrm{~min}$. Both the peak levels and overall responses were significantly different $(P$ $<0.01$ ). Plasma glucose in control animals just before cord cutting, $24 \pm 2 \mathrm{mg} / \mathrm{dl}$, rose to $32 \pm 5 \mathrm{mg} / \mathrm{dl}$ after cord cutting and remained elevated thereafter. Adrenalectomized animals demonstrated lower values initially $(16 \pm 2$ vs. $24 \pm 2 \mathrm{mg} / \mathrm{dl}, P$ $<0.01$ ), which fell after cord cutting to $6 \pm 1 \mathrm{mg} / \mathrm{dl}$ and remained $<10 \mathrm{mg} / \mathrm{dl}$ for the remainder of the study.

Plasma cortisol was compared in fetal plasma obtained just after catheterization during the delivery studies and before cord cutting. Despite placement of miniosmotic pumps programmed to deliver hydrocortisone at the daily production rate reported for this gestational age (17), plasma cortisol was lower in adrenalectomized than control animals, $1.1 \pm 0.2$ vs. $3.5 \pm 0.5 \mu \mathrm{g} / \mathrm{dl}$.

\section{Discussion}

Bilateral adrenalectomy or sham operation was performed in near-term ovine fetuses. After recovery in utero, the animals were delivered and comparisons were made between plasma catecholamine responses, cardiovascular status, pulmonary function, and surfactant release, and metabolic alterations associated with birth. Plasma epinephrine was undetectable in the adrenalectomized animals whereas control animals exhibited the usual prompt and sustained increase in circulating ephinephrine levels seen at birth (7). Norepinephrine in adrenalectomized animals showed a small incremental increase at birth followed by a gradual increase over the course of study.

Associated with the increase in circulating catecholamines in control animals, we observed immediate increases in heart rate, blood pressure and cardiac output. The isovolemic index of $\mathrm{LV}$ contractility, peak $d P / d t$, is directly correlated with $\mathrm{LV}$ preload and heart rate. In this study, the increased cardiac output in control animals was primarily related to increased heart rate since stroke volume did not differ between the groups. Although LV volumes were not measured, the comparable stroke volumes in control animals may have been 
achieved at lower LV end diastolic volume and greater ejection fraction since their heart rate was substantially greater. While it is accepted that $L V d P / d t$ is related to heart rate, the remarkable (doubling) increase of $L V d P / d t$ in the control animals suggests an increase of LV contractility as well as chronotropy.

At birth there is not only an increase in cardiac output and contractility but a redistribution of blood flow and closure of fetal vascular shunts. Recent studies by Rudolph and coworkers (18-20) on ventilated fetuses in utero suggest an increase in pulmonary blood flow occurs after lung inflation. Increased pulmonary venous return then leads to an increase in left ventricular output, presumably by the Frank-Starling mechanism (21). A further augmentation in pulmonary blood flow and left ventricular output is seen after oxygenation, however, left ventricular output does not reach newborn values even during brief periods of cord occlusion. These observations and our data suggest that although catecholamines may not be responsible for the increased pulmonary blood flow and shift to left ventricular dominance, the increase in circulating catecholamines at birth is important in the elevation of myocardial contractile state and increase in cardiac output as has been suggested previously (22). The importance of circulating catecholamines at birth during this period of increased cardiovascular demand also is supported by prior observations of hypotension and bradycardia in newborn puppies after adrenalectomy (23), impaired contractile responses to hypoxia in newborn piglets (24) and sheep (25) after adrenalectomy, and impaired contractile responses following adrenalectomy in newborn dogs compared to adults (26).

That the increases in cardiac output and cardiac contractility observed at birth are due to circulating epinephrine and not neurally mediated norepinephrine is suggested by the present studies and by our recent demonstration of comparable changes in cardiovascular responses at birth in chemically denervated and control sheep of similar gestational age (27). Myocardial sympathetic innervation of the near term fetal sheep is incomplete (28) although neurally mediated norepinephrine release still may play some role in reflex responses to increased cardiovascular demand (29).

Marked differences in pulmonary function between adrenalectomized and control animals were noted in the present study. This was most clearly illustrated by comparison of compliance and ventilatory efficiency index in the two groups of animals. Higher ventilatory pressures, faster rates and less successful control of arterial $\mathrm{PCO}_{2}$ were noted in the adrenalectomized animals and reflected by their lower VEI throughout the period of study (14). The differences in surfactant pool size and (visual) degree of aeration in the two groups of animals suggests that this may have been due to deficiency of alveolar surfactant. There is substantial evidence for a role for adrenergic control of surfactant secretion. Isoproterenol or epinephrine infusion into chronically instrumented fetal lambs increases surfactant release and decreases the rate of lung fluid production (30-32). Beta adrenergic agonists increase the amount of phospholipids recoverable in alveolar lavage in newborn rabbits (33) and are associated with a decreased incidence of respiratory distress syndrome in preterm human infants (34). Chemical adrenalectomy (35) or administration of an irreversible beta receptor blocker (36) decrease alveolar surfactant levels. These effects appear to be mediated via $\beta_{2^{-}}$adrenoceptors on type II pneumocytes $(37,38)$.
We observed significant alterations in the plasma levels of important energy substrates following umbilical cord cutting. FFA and plasma glucose increased abruptly in control animals and these changes were comparable to those noted previously in intact animals of this gestational age $(7,39)$. The increase in FFA levels in the adrenalectomized animals is most likely due to discharge of sympathetic neurons directly innervating brown adipose tissue. Innervation in this tissue is relatively dense at this gestational age in fetal sheep (40). The differences in FFA levels between control and adrenalectomized animals reflects the augmentation of lipolysis by circulating epinephrine.

Increased plasma glucose levels were noted in the control animals by $30-60 \mathrm{~min}$ of life and sustained thereafter. Adrenalectomized animals had lower baseline glucose levels that fell significantly after cord cutting and never rose thereafter. That this was due to epinephrine deficiency and deficient adrenergically mediated hepatic glycogenolysis is suggested by our recent studies in which we observed that plasma epinephrine levels necessary to stimulate increased plasma glucose are as low as $50-100 \mathrm{pg} / \mathrm{ml}$ in both term and preterm fetal sheep (41). Norepinephrine levels in excess of $2,000 \mathrm{pg} / \mathrm{ml}$ are necessary to increase plasma glucose. Epinephrine also stimulates pancreatic glucagon release in the near-term ovine fetus (42), but levels exceeding $1,000 \mathrm{pg} / \mathrm{ml}$ are required for this effect in term animals and nearly $2,500 \mathrm{pg} / \mathrm{ml}$ in $130 \pm 1 \mathrm{~d}$ animals (41). Moreover, fetal sheep at this developmental age are said to be relatively glucagon resistant (43). Thus, the major regulatory event promoting the availability of circulating glucose in the early newborn period appears to be an increase in plasma epinephrine level that stimulates an increase in hepatic glucose output.

We gave replacement doses of hydrocortisone in miniosmotic infusion pumps programmed to deliver the reported daily production rate of cortisol to the adrenalectomized animals. Nonetheless, immunoreactive plasma cortisol levels were lower in adrenalectomized than control animals. This is most likely explained by a higher daily production rate in the postoperatively stressed sham-operated animals. It is unlikely that this influenced the results of this study. The cortisol levels in the adrenalectomized animals were comparable to those reported in chronically catheterized animals at this gestational age (18), demonstrating that the adrenalectomized animals were not cortisol deficient. Liver glycogen accumulation has been shown to be dependent on adrenocortical function in fetal lambs; adrenalectomy causes depletion of liver glycogen content (44). Pulmonary surfactant metabolism is also an important adrenocortical-related maturational event although the mechanism(s) is complex (45). However, in our studies the duration of adrenalectomy was relatively brief and induced after the onset of the majority of adrenocortical-related maturational events (45). We therefore believe that the cortisol differences observed in the present study were not sufficient in themselves to account for our observations.

In summary, we performed complete surgical adrenalectomy on ovine fetuses that were then allowed to recover in utero. The animals were then delivered near term and their catecholamine responses, a variety of cardiovascular parameters, pulmonary function, pulmonary surfactant release, and release of energy substrates were compared with an identical group of sham operated lambs. Our results suggest that the 
surge of catecholamines at birth is primarily of adrenal origin and that increased circulating catecholamines are vital to many of the physiologic adaptations at birth.

\section{Acknowledgments}

The authors also wish to thank Alan Jobe, M.D. for advice during these experiments and Prescilla Barrette for preparation of the manuscript.

Supported by grants from the U.S. Public Health Service HD-18014 and HD-12714, and a Basil O'Connot Starter Research Grant from the National Foundation March of Dimes.

\section{References}

1. Rudolph, A. M. 1970. The changes in the circulation after birth. Their importance in congenital heart disease. Circulation. XLI:343359.

2. Lagercrantz, H., and P. Bistoletti. 1977. Catecholamine release in the newborn infant at birth. Pediatr. Res. 11:889-893.

3. Jones, C. M., III, and F. C. Greiss, Jr. 1982. The effect of labor on maternal and fetal circulating catecholamines. Am. J. Obstet. Gynecol. 144:149-153.

4. Padbury, J. F., B. Roberman, T. H. Oddie, C. J. Hobel, and D. A. Fisher. 1982. Fetal catecholamine release in response to labor and delivery. Obstet. Gynecol. 60:607-611.

5. Jones, C. T., and R. O. Robinson. 1975. Plasma catecholamines in foetal and adult sheep. J. Physiol. 248:15-33.

6. Eliot, R. J., A. H. Klein, T. H. Glatz, P. W. Nathanielsz, and D. A. Fisher. 1981. Plasma notepinephrine, epinephrine, and dopamine concentrations in maternal and fetal sheep during spontaneous parturition and in premature sheep during cortisol-induced parturition. Endocrinology. 108:1678-1682.

7. Padbury, J. F., D. H. Polk, J. P. Newnham, and R. W. Lam. 1985. Neonatal adaptation: greater sympathoadrenal response in preterm than full-term fetal sheep at birth. Am. J. Physiol. 248 (Endocrinol. Metab. 11):E443-E449.

8. Liggins, G. C., P. W. Nathanielsz, and M. Silver. 1982. Methods of investigation of the hypothalamo-pituitary-adrenal axis and renal function in the fetal sheep; experimental preparations that alter the duration of gestation. In Animal Models in Fetal Medicine. P. W. Nathanielsz, editor. Elsevier Biomedical Press, Amsterdam. 1-23.

9. Jacobs, H., A. Jobe, M. Ikegami, and S. Jones. 1985. Accumulation of alveolar surfactant following delivery and ventilation of premature lambs. Exp. Lung Res. 8:125-140.

10. Bartlett, G. R. 1959. Phosphorous assay in column chromatography. J. Biol. Chem. 243:466-468.

11. Peuler, J. D., and G. A. Johnson. 1977. Simultaneous single isotope radioenzymatic assay of plasma norepinephrine, epinephrine and dopamine. Life Sci. 21:625-636.

12. Goloni, F. G., and L. C. Sardina. 1973. Colorimetric microdetermination of free fatty acids. Clin. Chem. 19:419-424.

13. Notter, R. H., E. A. Egan, M. S. Kwong, B. A. Holm, and D. L. Shapiro. 1985. Lung surfactant replacement in premature lambs with extracted lipids from bovine lung lavage. Effects of dose, dispersion technique, and gestational age. Pediatr. Res. 19:569-577.

14. Sokal, R., and F. Rohlf. 1969. Two-way analysis of variance. In Biometry. R. Emerson, D. Kennedy, R. B. Park, G. W. Beadle, and D. M: Whitaker, editors. Freeman, San Francisco.

15. Breall, J. A., A. M. Rudolph, and M. A. Heymann. 1984. Role of thyroid hormone in postnatal circulatory and metabolic adjustments. J. Clin. Invest. 73:1418-1424.

16. Heymann, M. A., R. K. Creasy, and A. M. Rudolph. 1973. Quantitation of blood flow patterns in the foetal lamb in utero. In Proceedings of the Sir Joseph Barcroft Centenary Symposium: Foetal and Neonatal Physiology. Cambridge University Press, Cambridge. 129-135.
17. Nathanielsz, P. W., R. S. Comline, M. Silver, and R. B. Paisey. 1972. Cortisol metabolism in the fetal and neonatal sheep. J. Reprod. Fertil. 16:39-59.

18. Rudolph, A. M., D. F. Teitel, H. S. Iwamoto, and C. A. Gleason. 1986. Ventilation is more important than oxygenation in reducing pulmonary vascular resistance at birth. Pediatr. Res. 20:439a. (Abstr.)

19. Teitel, D. F., H. S. Iwamoto, and A. M. Rudolph. 1986. Redistribution of cardiac output during birth simulation. Pediatr. Res. 20:372a. (Abstr.)

20. Iwamoto, H. S., D. F. Teitel, and A. M. Rudolph. 1986. Effects of birth-related events on the cardiovascular system. Pediatr. Res. 20:350a. (Abstr.)

21. Baylen, B. G., H. Ogata, M. Ikegami, H. Jacobs, A. Jobe, and G. C. Emmanouilides. 1986. Left ventricular performance and contractility before and after volume infusion: a comparative study of preterm and full-term newborn lambs. Circulation. 73:1042-1049.

22. Riemenschneider, T. A., R. B. Brenner, and D. T. Mason. 1981. Maturational changes in myocardial contractile state of newborn lambs. Pediatr. Res. 15:349-356.

23. Geis, W. P., C. J. Tatooles, D. V. Priola, and W. F. Friedman. 1975. Factors influencing neurohumoral control of the heart in the newborn dog. Am. J. Physiol. 228:1685-1689.

24. Lee, J. C., C. Werner, and S. E. Downing. 1980. Adrenal contribution to cardiac responses elicited by acute hypoxia in piglets. $\mathrm{Am}$. J. Physiol. 239(Heart Circ. Physiol. 8):H751-H755.

25. Downing, S. E., and J. C. Lee. 1983. Analysis of cardiac adrenergic mechanisms in hypoxic lambs. Am. J. Physiol. 244(Heart Circ. Physiol. 13):H222-H227.

26. Erath, H. G., R. C. Boerth, and T. P. Graham, Jr. 1982. Functional significance of reduced cardiac sympathetic innervation in the newborn dog. Am. J. Physiol. 243(Heart Circ. Physiol. 12):H20-H26.

27. Agata, Y., J. F. Padbury, J. K. Ludlow, D. H. Polk, and J. A. Humme. 1986. The effect of chemical sympathectomy on catecholamine release at birth. Pediatr. Res. 20:1338-1344.

28. Lebowitz, E. A., J. S. Novick, and A. M. Rudolph. 1972. Development of myocardial sympathetic innervation in the fetal lamb. Pediatr. Res. 6:887-893.

29. Clyman, R. I., D. Teitel, J. Padbury, C. Roman, and F. Murray. 1986. PDA: Role of catecholamines and increased contractile state. Clin. Res. In press.

30. Walters, D. V., and R. E. Olver. 1978. The rolè of catecholamines in lung liquid absorption at birth. Pediatr. Res. 12:239-242.

31. Lawson, E. E., E. R. Brown, J. S. Torday, D. L. Madansky, and H. W. Taeusch, Jr. 1978. The effect of epinephrine on tracheal fluid flow and surfactant efflux in fetal sheep. Am. Rev. Respir. Dis. 118:1023-1026.

32. Brown, M. J., R. E. Olver, C. A. Ramsden, L. B. Strang, and D. V. Walters. 1983. Effects of adrenaline and of spontaneous labour on the secretion and absorption of lung lipid in the fetal lamb. $J$. Physiol. 344:137-152.

33. Enhorning, G., D. Chamberlain, C. Contreras, R. Burgoyne, and B: Robertson. 1977. Isoxsuprine-induced release of pulmonary surfactant in the rabbit fetus. Am. J. Obstet. Gynecol. 129:197-202.

34. Bergman, B. 1981. Beta-mimetics and the preterm neonatal lung. An experimental and clinical study. In Acta Physiological Scandinavica Supplementum 497. B. Bergman, editor. Goteborg, Sweden. $1-52$.

35. Padbury, J. F., H. C. Jacobs, R. W. Lam, D. Conaway, A. H. Jobe, and D. A. Fisher. 1984. Adrenal epinephrine and the regulation of pulmonary surfactant release in neonatal rabbits. Exp. Lung Res. 7:177-186.

36. MacDonald, J. V., L. W. Gonzales, P. L. Ballard, J. Pitha, and J. M. Roberts. Lung $\beta$-adrenoceptor blockade affects perinatal surfactant release but not lung water. J. Appl. Physiol. In press.

37. Sommers-Smith, S. K., and G. Giannopoulos. 1983. Identif- 
cation of $\beta$-adrenergic receptors in pulmonary alveolar type II cells. Life Sci. 33:2071-2078.

38. Brown, L. A. S., and W. J. Longmore. 1981. Adrenergic and cholinergic regulation of lung surfactant secretion in the isolated perfused rat lung and in the alveolar type II cell in culture. J. Biol. Chem. 256:66-72.

39. Van Duyne, C. M., H. R. Parker, R. J. Havel, and L. W. Holm. 1960. Free fatty acid metabolism in fetal and newborn sheep. Am. J. Physiol. 199(6):987-990.

40. Gemmell, R. T., and G. Alexander. 1978. Ultrastructural development of adipose tissue in foetal sheep. Aust. J. Biol. Sci. 31:505515.

41. Padbury, J. F., J. K. Ludlow, M. G. Ervin, H. C. Jacobs, and J. Humme. 1987. Thresholds for the physiologic effects of plasma cate- cholamines in fetal sheep. Am. J. Physiol. 252(Endocrinol. Metab.):E530-E537.

42. Sperling, M. A., R. A. Christensen Supriya Ganguli, and R. Anand. 1980. Adrenergic modulation of pancreatic hormone secretion in utero. Studies in fetal sheep. Pediatr. Res. 14:203-208.

43. Devaskar, S. U., S. Ganguli, D. Styer, U. P. Devaskar, and M. A. Sperling. 1984. Glucagon and glucose dynamics in sheep: evidence for glucagon resistance in the fetus. Am. J. Physiol. 246(Endocrinol. Metab. 9):E256-E265.

44. Barnes, R. J., R. S. Comline, and M. Silver. 1976. The effects of bilateral adrenalectomy or hypophysectomy of the foetal lamb in utero. J. Physiol. 264:429-447.

45. Liggins, G. C. 1976. Adrenocortical-related maturational events in the fetus. Am. J. Obstet. Gynecol. 126:931-941. 